06,11

\title{
Структура, зеренное строение и диэлектрические свойства керамик твердых растворов $\mathrm{YCu}_{x} \mathrm{Mn}_{1-x} \mathrm{O}_{3}$
}

\author{
(C) А.В. Назаренко ${ }^{1}$, А.В. Павленко 1,2, К.Г. Абдулвахидов ${ }^{2}$ \\ ${ }^{1}$ Федеральный исследовательский центр Южный научный центр РАН, \\ Ростов-на-Дону, Россия \\ 2 Южный фредеральный университет, \\ Ростов-на-Дону, Россия \\ E-mail: avnazarenko1@gmail.com
}

Поступила в Редакцию 23 октября 2020 г.

В окончательной редакции 23 октября 2020 г.

Принята к публикации 23 октября 2020 г.

\begin{abstract}
Методом твердофазных реакций с последующим спеканием по обычной керамической технологии были изготовлены керамики твердых растворов системы $\mathrm{YCu}_{x} \mathrm{Mn}_{1-x} \mathrm{O}_{3} \mathrm{c} x=0.05,0.10,0.15$. Проведены исследования их структуры, микроструктуры и диэлектрических свойств, включающие измерение температурночастотных зависимостей относительной диэлектрической проницаемости и тангенса угла диэлектрических потерь и удельной электропроводности. Установлено, что в керамиках формируется преимущественно гексагональная фаза, при этом их зеренная структура неоднородная, а синтез происходил с образованием жидких фаз эвтектического происхождения. Показано, что аномальное поведение диэлектрических характеристик при $T=30-200^{\circ} \mathrm{C}$ во всех керамиках связано с проявлением эффектов межслоевой поляризации, а при $T=222^{\circ} \mathrm{C}(x=0.05), 234^{\circ} \mathrm{C}(x=0.10)$ и $247^{\circ} \mathrm{C}(x=0.15)-$ с „изоструктурным“ переходом, являющимся промежуточным между сегнетоэлектрической и параэлектрической фазами.
\end{abstract}

Ключевые слова: мультиферроик, манганит иттрия, твердый раствор, диэлектрическая проницаемость, микроструктура.

DOI: 10.21883/FTT.2021.03.50594.229

\section{1. Введение}

В настоящее время мультиферроикам уделяют особое внимание из-за большого потенциала их применения в современных технологических отраслях. Это связано c взаимодействием между различными подсистемами в таких структурах [1], главным образом - сегнетоэлектрической (СЭ) и магнитной [2]. Редкоземельные манганиты $R e \mathrm{MnO}_{3}(\operatorname{Re}-$ редкоземельный элемент) являются типичными представителями данной группы материалов и в зависимости от ионного радиуса $R e$ при комнатной температуре могут образовываться как с орторомбической (Orth) структурой (Re - от La до Dy), так и с гексагональной $(\mathrm{Hex})(R e-$ от Но до $\mathrm{Lu})$, что связывается с толеранс-фактором Гольдшмидта [3]:

$$
t=\frac{r_{A}+r_{O}}{\sqrt{2}\left(r_{B}+r_{O}\right)} .
$$

Близким по структуре и свойствам к $\operatorname{Re} \mathrm{MnO}_{3}$ является манганит иттрия $\left(\mathrm{YMnO}_{3}\right)$. Он занимает особую позицию среди манганитов, что обусловлено возможностью его изготовления в стабильной при комнатной температуре как в Orth-фазе, так и в Нех-фазе $[4,5]$. Синтезируется он при достаточно высоких температуpax $\left(T_{\text {синт }} \sim 1300 \mathrm{~K}\right)$. При комнатной температуре он является сегнетоэлектриком (СЭ) с пространственной группой симметрии $P 6_{3} \mathrm{~cm}$, в котором поляризация является следствием малых смещений в подрешетке иттрия [6]. Переход в параэлектрическую фазу протекает при $T_{C} \approx 900 \mathrm{~K}$, а антиферромагнитное (АФМ) упорядочение возникает ниже температуры $T_{\mathrm{N}} \approx 80 \mathrm{~K}[7,8]$. Перовскитная Orth-фаза (пространственная группа симметрии Рnта [9]), образующаяся при высоких давлениях и температурах, не является устойчивой повторный отжиг без приложения давления переводит к образованию Нех-фазы [10]. Однако в твердых растворах (TP) на основе $\mathrm{YMnO}_{3}$ орторомбическая фаза достаточно устойчива, хотя и формируется часто „в паре“ с гексагональной [11]. Одной из причин этого является возможность катионов марганца переходить, например, в состояние $\mathrm{Mn}^{4+}$, которое соответствует наименьшему ионному радиусу марганца [12], за счет чего толеранс-фактор (1) возрастает. Это связанно с низкими температурами превращений в ,цепочке“ $\mathrm{Mn}^{(4+)} \mathrm{O}_{2}$ $(873 \mathrm{~K}) \rightarrow \mathrm{Mn}_{2}^{(3+)} \mathrm{O}_{3}(1173 \mathrm{~K}) \rightarrow \mathrm{Mn}_{3}^{(2+)+(3+)} \mathrm{O}_{4}(1573 \mathrm{~K})$, которые могут быть еще более низкими в многоэлементных композициях и осуществляться как при синтезе, так и при спекании материала. Это может привести к возникновению в данных структурах ферримагнитных свойств, как это имеет место, например, в манганитах висмута-лантана [13]. Как показал анализ литературы, внедрение более чем 20\% меди в $\mathrm{YMnO}_{3}$ приводит к образованию перовскитной фазы, при меньших же концентрациях преобладает Нех-фаза с примесями [14]. Целью настоящей работы является исследование структуры, микроструктуры и диэлектрических свойств в 
Структурные параметры системы ТP $\mathrm{YCu}_{x} \mathrm{Mn}_{1-x} \mathrm{O}_{3}$ при комнатной температуре

\begin{tabular}{c|c|c|c|c}
\hline Параметр & $\mathrm{YMnO}_{3}[16]$ & $\mathrm{YCu}_{0.05} \mathrm{Mn}_{0.95} \mathrm{O}_{3}$ & $\mathrm{YCu}_{0.10} \mathrm{Mn}_{0.90} \mathrm{O}_{3}$ & $\mathrm{YCu}_{0.15} \mathrm{Mn}_{0.85} \mathrm{O}_{3}$ \\
\hline$a, b, \AA$ & $6.139(0)$ & $6.145(7)$ & $6.141(7)$ & $6.139(8)$ \\
$c, \AA$ & $11.410(0)$ & $11.385(7)$ & $11.376(7)$ & $11.373(9)$ \\
Orth-фаза & - & + & + & - \\
$V, \AA^{3}(Z=6)$ & 61.90 & 62.07 & 61.94 & 61.89 \\
$\rho x$-ray, g/cm & - & 5.132 & 5.143 & 5.147 \\
$\mathrm{Y} 1-O 1$ & $2.279(8)$ & $2.283(2)$ & $2.315(8)$ & $2.278(5)$ \\
$\mathrm{Y} 1-\mathrm{O} 2$ & $2.342(4)$ & $2.342(3)$ & $2.321(6)$ & $2.341(5)$ \\
$\mathrm{Y} 1-\mathrm{O} 3$ & $2.332(2)$ & $2.321(5)$ & $2.258(3)$ & $2.323(7)$ \\
$\mathrm{Y} 2-\mathrm{O} 1$ & $2.255(9)$ & $2.265(0)$ & $2.295(3)$ & $2.257(3)$ \\
$\mathrm{Y} 2-\mathrm{O} 2$ & $2.323(5)$ & $2.312(5)$ & $2.266(8)$ & $2.318(6)$ \\
$\mathrm{Y} 2-\mathrm{O} 4$ & $2.449(7)$ & $2.466(1)$ & $2.550(7)$ & $2.447(7)$ \\
$\mathrm{Mn}-\mathrm{O} 1$ & $1.838(2)$ & $1.832(1)$ & $1.819(3)$ & $1.831(3)$ \\
$\mathrm{Mn}-\mathrm{O} 2$ & $1.867(9)$ & $1.866(2)$ & $1.876(1)$ & $1.863(2)$ \\
$\mathrm{Mn}-\mathrm{O} 3$ & $2.061(0)$ & $2.063(4)$ & $2.063(7)$ & $2.061(3)$ \\
$\mathrm{Mn}-\mathrm{O} 4$ & $2.055(8)$ & $2.057(7)$ & $2.055(6)$ & $11055(9)$ \\
$\mathrm{Mn} / \mathrm{Cu}-\mathrm{O} 3-\mathrm{Mn}$ & $118.009(7)$ & $117.992(6)$ & $117.840(2)$ & $119.007(9)$ \\
$\mathrm{Mn} / \mathrm{Cu}-\mathrm{O} 4-\mathrm{Mn}$ & $119.388(2)$ & $119.437(9)$ & $119.502(7)$ &
\end{tabular}

интервале температур $30-400^{\circ} \mathrm{C}$ керамик твердых растворов $\mathrm{YCu}_{x} \mathrm{Mn}_{1-x} \mathrm{O}_{3}$ с $\left.x=5-15 \%\right)$.

\section{2. Методы получения и исследования}

При синтезе керамик твердых растворов $\mathrm{YCu}_{x} \mathrm{Mn}_{1-x} \mathrm{O}_{3} \quad(x=0.05,0.10$ и 0.15$)$ использовались простые оксиды $\mathrm{Y}_{2} \mathrm{O}_{3}, \mathrm{CuO}$ и $\mathrm{Mn}_{2} \mathrm{O}_{3}$ качеством не ниже „ч.д.а.“. Стехиометрические смеси образцов перемешивались в этиловом спирте в течение $1 \mathrm{~h}$, после чего брикетировались в диски диаметром $5 \mathrm{~mm}$. Стадия синтеза проводилась поэтапно при температурах $T_{1}=850^{\circ} \mathrm{C}\left(\tau_{1}=3 \mathrm{~h}\right)$ и $T_{2}=1160^{\circ} \mathrm{C}\left(\tau_{1}=2 \mathrm{~h}\right)$. Дальнейшее спекание проводилось с использованием традиционной керамической технологии.

Для исследования фазового состава и кристаллической структуры объектов использовался метод рентгеноструктурного анализа с использованием дифрактометра Bruker D2 PHASER. Изучение зеренного строения керамик проводилось на 3D-сканирующем лазерном микроскопе Keyence VK-9700.

Температурные зависимости относительной диэлектрической проницаемости $\varepsilon^{\prime} / \varepsilon_{0}$, и тангенса угла диэлектрических потерь, $\operatorname{tg} \delta$, в диапазоне частот $f=10^{2}-10^{5} \mathrm{~Hz}$ и удельного электрического сопротивления - образцов при $T=300-700 \mathrm{~K}$ получали с помощью измерительного стенда на базе LCR-метра HIOKI 35-50 с использованием методики № ГСССД МЭ 184-2011. Для проведения измерений на поверхность керамики наносилась паста auromal 38 (DODUCO GmBH). Относительная диэлектрическая проницаемость $\left(\varepsilon / \varepsilon_{0}\right)$ определялась из соотношения $C=\varepsilon \varepsilon_{0} S / h$, где $C$ - емкость структуры, $h-$ толщина слоя сегнетоэлектрика, $S-$ площадь электрода, $\varepsilon_{0}=8.854 \cdot 10^{-12} \mathrm{~F} / \mathrm{m}$ - электрическая постоянная.

\section{3. Результаты и обсуждение}

В изготовленных керамических образцах, по данным РФА и РСА, частично представленных нами ранее в [15], формируется преимущественно гексагональная фаза. В ТР с концентрацией $\mathrm{Cu}$ ниже $15 \%$ кроме Нехфазы имеется небольшие примеси, а также перовскитная фаза, количество которой снижается с увеличением концентрации меди (рис. 1). Тенденция в изменении параметров гексагональной ячейки объектов (таблица) с

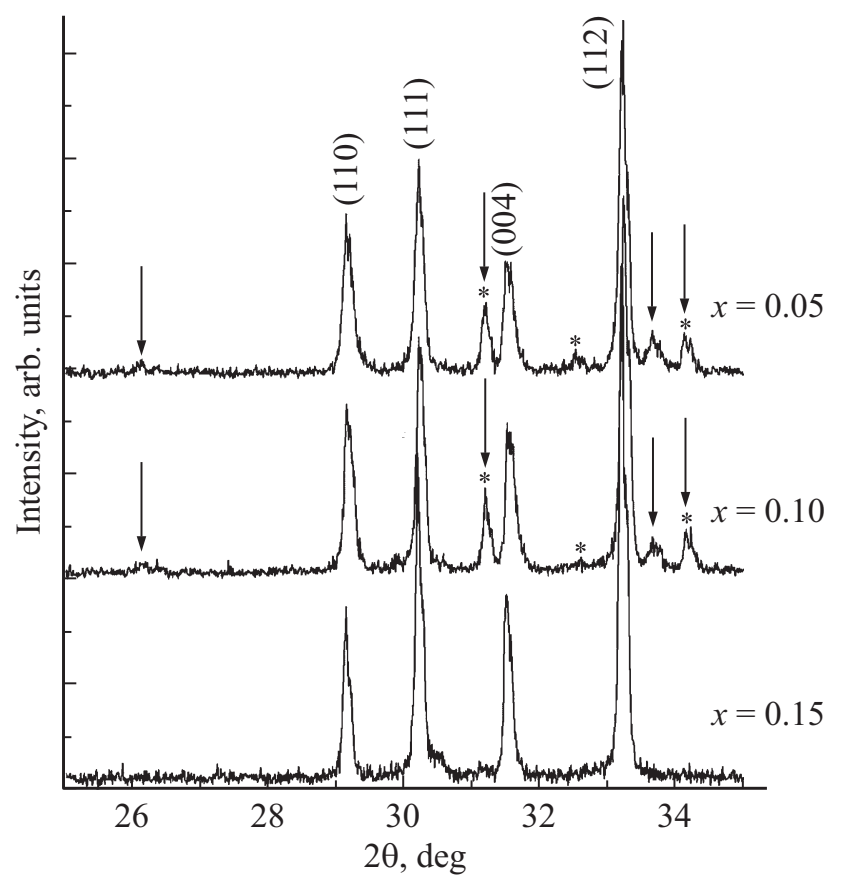

Рис. 1. Рентгенограммы системы ТР $\mathrm{YCu}_{x} \mathrm{Mn}_{1-x} \mathrm{O}_{3}$ при комнатной температуре. Стрелки - Orth-фаза, $(*)$ - примесь $\mathrm{YMn}_{2} \mathrm{O}_{5}$. 
ростом концентрации меди свидетельствует о частичном ее вхождении в базовую структуру. Изменение длин связи и углов позволяет заключить, что уменьшение объема происходит не только за счет изменения линейных размеров ячейки, но и ее формы. При этом можно проследить аномальный характер концентрационного изменения геометрии элементарной ячейки. При общем снижении объема/параметров наблюдается особенность в ТР с $x=0,10$. Это возможно говорит о различной конфигурации валентных состояний марганца.

После спекания при температуре $T_{2}=1160^{\circ} \mathrm{C}$ керамики $\mathrm{YCu}_{0.05} \mathrm{Mn}_{0.95} \mathrm{O}_{3}$ и $\mathrm{YCu}_{0.10} \mathrm{Mn}_{0.90} \mathrm{O}_{3}$ обладали меньшей плотностью, чем $\mathrm{YCu}_{0.15} \mathrm{Mn}_{0.85} \mathrm{O}_{3}$, что можно было хорошо наблюдать даже при их визуальном осмотре. Это так же проявилось при изучении поверхности механических сколов керамик системы ТP $\mathrm{YCu}_{x} \mathrm{Mn}_{1-x} \mathrm{O}_{3}$ методами оптической микроскопии, представленные на рис. 2-4. Характер механического скола, прошедшего как по самим зернам, так и по их границам, позволил нам во всех случаях достаточно хорошо проанализировать форму и габитусы кристаллитов, а также межкристаллитное пространство. Видно, что зеренная структура керамик достаточно неоднородна, при этом как размеры зерен, так и их форма достаточно сильно варьируются. Это может быть обусловлено, в том числе, и выявленным выше сложным фазовым составов керамик. В целом, выделяются 3 отличающихся группы зерен: I - крупные конгломераты мелкозернистых кристаллитов размером 8-15 $\mu \mathrm{m}$, II - кристаллиты правильной формы, близкой к параллелепипед-образной, размером $2-5 \mu \mathrm{m}$, III - кристаллиты с округлой формой размером 5-10 $\mu \mathrm{m}$ (рис. 2,3). Ввиду фиксирования межкристаллитных прослоек толщиной от 0.5 до $2 \mu \mathrm{m}$, „обволакивающих“ кристаллиты, с преобладающим содержанием меди [15], формирование зерен типа III, может быть следствием частичного изменения характера спекания керамик в рамках обычной керамической технологии: от твердофазного к спеканию с участием жидкой фазы (ЖФ) (рис. 4). Учитывая, что в случае твердофазных реакций [17] практически всегда по технологическим причинам не весь объем исходных реагентов участвует в синтезе и, как следствие, остаются непрореагировавшие сырьевые компоненты, очевидно присутствие в шихтах определенного количества, не вошедшего в структуру $\mathrm{CuO}$, с которым может быть связано образование ЖФ [18]. Анализ фазовой диаграммы системы $\mathrm{Cu}-\mathrm{O}$ показывает, что в случае частичной потери кислорода, которая неизбежна в рамках ОКТ при температуре спекания, температура плавления оксида $\mathrm{CuO}_{1-\delta}$ может снижаться до $1090^{\circ} \mathrm{C}$. Учитывая же возможность образования ЖФ с участием ионов меди в результате образования эвтектических смесей, нельзя исключить возможность еще большего снижения температуры [19], что мы фиксируем вероятнее всего.

На рис. 5 приведены зависимости $\varepsilon^{\prime} / \varepsilon_{0}(T)$ и $\operatorname{tg} \delta(T)$ керамик ТР $\mathrm{YCu}_{x} \mathrm{Mn}_{1-x} \mathrm{O}_{3} \quad$ с $x=0.05,0.10$ и 0.15 в рассматриваемом температурно-частотном диапазоне.

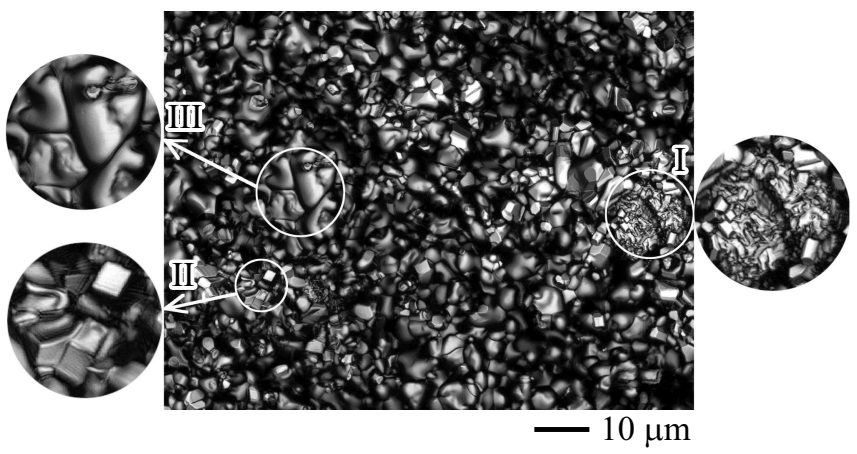

Рис. 2. Микроструктура участка поперечного скола состава $\mathrm{YCu}_{0.05} \mathrm{Mn}_{0.95} \mathrm{O}_{3}$.

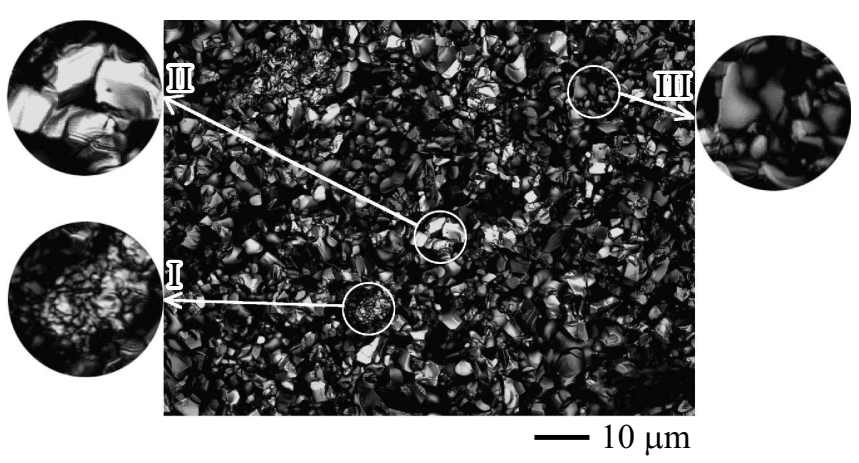

Рис. 3. Микроструктура состава участка поперечного скола $\mathrm{YCu}_{0.10} \mathrm{Mn}_{0.90} \mathrm{O}_{3}$.

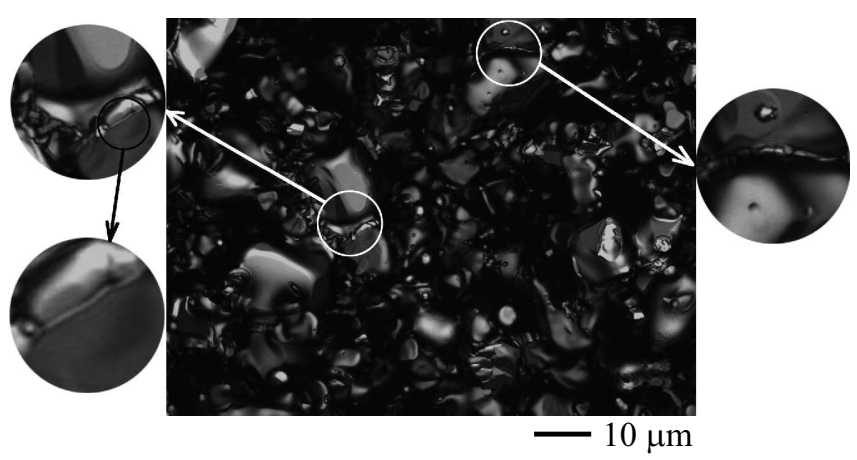

Рис. 4. Микроструктура состава участка поперечного скола $\mathrm{YCu}_{0.15} \mathrm{Mn}_{0.85} \mathrm{O}_{3}$.

При комнатной температуре керамики характеризовались невысокими значениями относительной диэлектрической проницаемости (40-80) и высокими значениями тангенса угла диэлектрических потерь (до 5), что является следствием высокой сквозной электропроводности керамик $\left(\gamma_{\mathrm{st}} \sim 10^{-6}(\Omega \cdot \mathrm{m})^{-1}\right)$, дающей прямой вклад $\gamma_{\text {st }} /\left(\varepsilon_{0} \omega\right)$ в значение $\operatorname{tg} \delta[20]$. На кривых $\varepsilon^{\prime} / \varepsilon_{0}(T)$ во всех случаях по мере роста температуры при $T=25-120^{\circ} \mathrm{C}$ формировались максимумы при $T_{m}$, положение которых при увеличении $f$ с $10^{3} \mathrm{~Hz}$ до $10^{5} \mathrm{~Hz}$ смещалось в высокотемпературную область: для $\mathrm{YCu}_{0.05} \mathrm{Mn}_{0.95} \mathrm{O}_{3}-$ с $4^{\circ} \mathrm{C}$ до $75^{\circ} \mathrm{C}$, для $\mathrm{YCu}_{0.10} \mathrm{Mn}_{0.90} \mathrm{O}_{3}-$ с $38^{\circ} \mathrm{C}$ до $86^{\circ} \mathrm{C}$ 

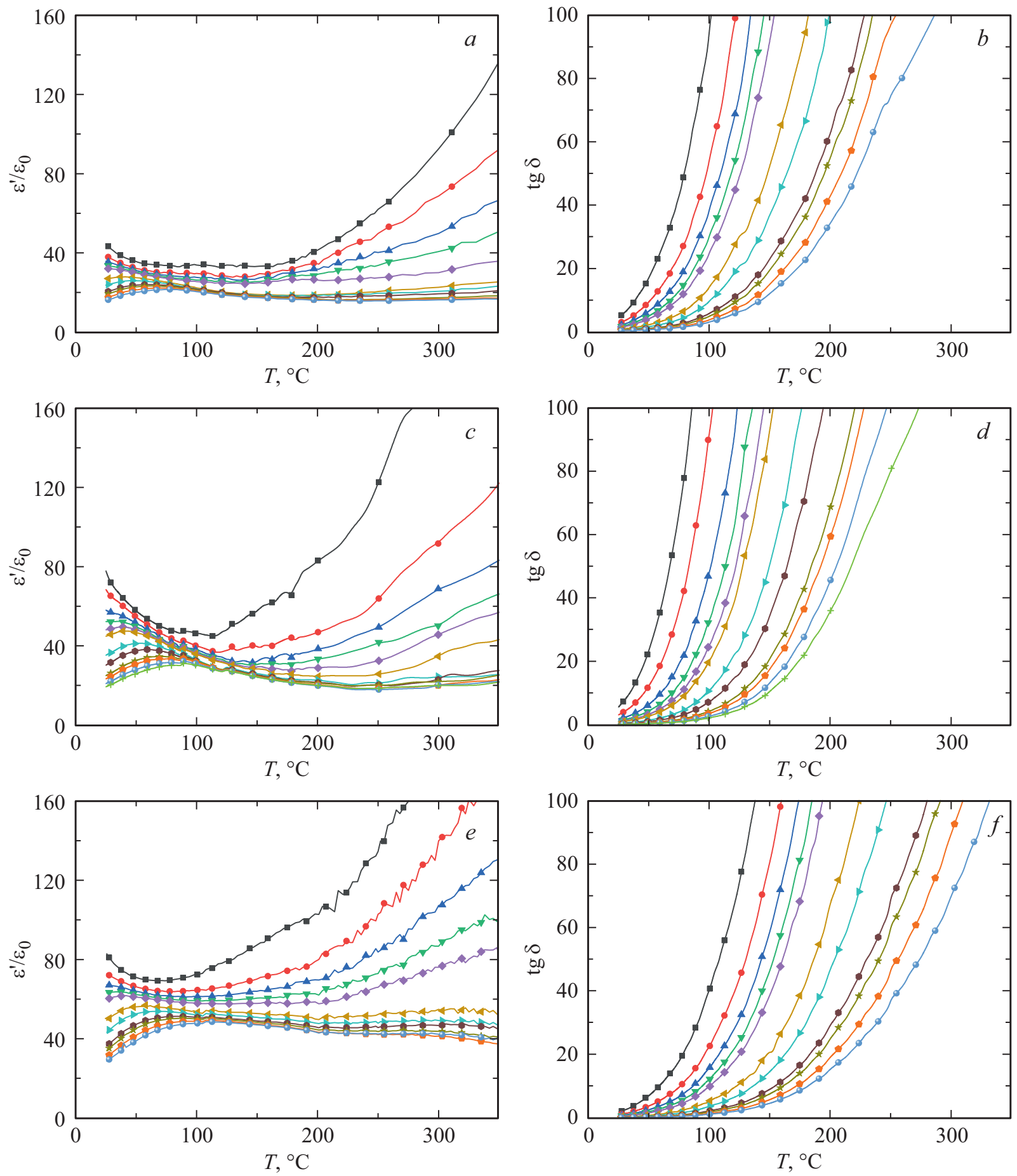

Рис. 5. Зависимости $\varepsilon^{\prime} / \varepsilon_{0}(T)$ и $\operatorname{tg} \delta(T)$ в интервале $T=30-350^{\circ} \mathrm{C}$ и $f=10^{2}-10^{5} \mathrm{~Hz}$ для ТР керамик $\mathrm{YCu}_{0.05} \mathrm{Mn}_{0.95} \mathrm{O}_{3}(a, b)$, $\mathrm{YCu}_{0.10} \mathrm{Mn}_{0.90} \mathrm{O}_{3}(c, d)$ и $\mathrm{YCu}_{0.15} \mathrm{Mn}_{0.85} \mathrm{O}_{3}(e, f)$.

и для $\mathrm{YCu}_{0.15} \mathrm{Mn}_{0.85} \mathrm{O}_{3}-$ с $40^{\circ} \mathrm{C}$ до $102^{\circ} \mathrm{C}$. При более высоких температурах значения $\varepsilon^{\prime} / \varepsilon_{0}$ монотонно возрастали. На зависимостях $\operatorname{tg} \delta(T)$, в свою очередь, аномалии в этой области идентифицировались достаточно слабо и главным образом при наибольших частотах в виде „горбов“ или точек перегиба, что обусловлено отмеченным ранее вкладом в диэлектрический отклик сквозной электропроводности объектов, возрастающей по мере роста температуры (рис. 6). Зависимость $T_{m}(f)$ в анализируемом частотном диапазоне для всех керамик описывалась соотношением Аррениуса (рис. 6)

$$
f=f_{0} \exp \left(E_{\text {act }} /\left(k t_{\mathrm{m}}\right)\right)
$$

где $f_{0}$ - частота попыток преодоления потенциального барьера $E_{\text {act }}, k$ - постоянная Больцмана. 


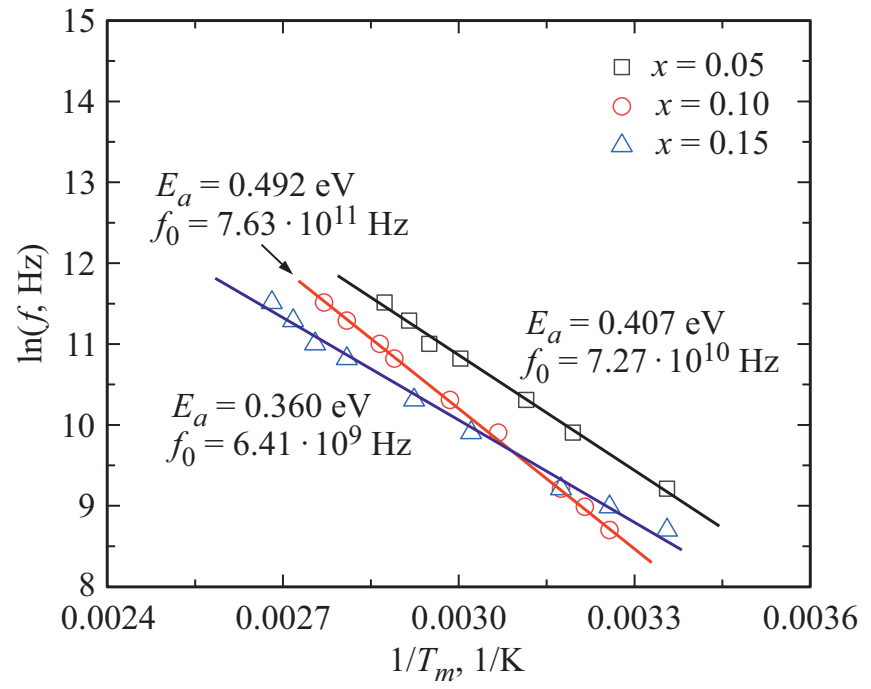

Рис. 6. Зависимость $\ln (f)$ от $1 / T$ керамик $\mathrm{YCu}_{x} \mathrm{Mn}_{1-x} \mathrm{O}_{3}$ с $x=0.05,0.10$ и 0.15. Прямые линии - результат расчета согласно соотношению Аррениуса (2).

Зависимости удельной электропроводности исследуемых керамик от температуры, построенные в координатах Аррениуса приведены на рис. 7. Видно, что во всех случаях в интервале температур $25-400^{\circ} \mathrm{C}$ зависимость $\ln (\gamma)(1 / T)$ носит фрагментарно линейный характер (для $\mathrm{YCu}_{0.05} \mathrm{Mn}_{0.95} \mathrm{O}_{3} 25-247^{\circ} \mathrm{C}$ - I и $247-400^{\circ} \mathrm{C}$ - II; для $\mathrm{YCu}_{0.10} \mathrm{Mn}_{0.90} \mathrm{O}_{3} \quad 25-234^{\circ} \mathrm{C}$ - I и $234-400^{\circ} \mathrm{C}$ - II; для $\mathrm{YCu}_{0.15} \mathrm{Mn}_{0.85} \mathrm{O}_{3} 30-222^{\circ} \mathrm{C}-$ I и $\left.222-400^{\circ} \mathrm{C}-\mathrm{II}\right)$, что свидетельствует о термоактивационных механизмах электропроводности материалов в анализируемом диапазоне температур. Рассчитанные значения энергии активации позволяют связать проводимость главным образом с кислородными вакансиями [20]. Высокая элект- ропроводность приводит к тому, что даже в слабых электрических полях в материале происходит накопление зарядов на различного рода границах раздела, отличающиеся диэлектрическими свойствами (проводимостью и диэлектрической проницаемостью) [20]. Их наличие установлено нами, частично, при анализе микроструктуры керамик (см. рис. 2), а также обусловлено существованием, учитывая симметрию объектов, спонтанной поляризации, в экранировке которой участвуют свободные заряды материала. Все это как раз-таки и способствует проявлению эффектов межслоевой поляризации (максвелл-вагнеровская поляризация) и сопутствующей ей диэлектрической релаксации, что мы и фиксировали на зависимостях $\varepsilon^{\prime} / \varepsilon_{0}(T)$ и $\operatorname{tg} \delta(T)$. Близость рассчитанных значений $E_{\text {act }}$ для всех керамик и сопоставимый температурный диапазон, где мы фиксируем соответствующие релаксационные максимумы, свидетельствует о едином механизме, дающим основной вклад в диэлектрический отклик для всех исследуемых керамиках.

$\mathrm{C}$ увеличением концентрации $\mathrm{Cu}$, температура излома на кривых $\ln (\gamma)$ от $1 / T$, свидетельствующая об изменении энергии активации электропроводности материала, смещалась в высокотемпературную область с 495 до $520 \mathrm{~K}$. Учитывая данные работы [7,21,22], это может быть связано с „изоструктурной“ фазовой перестройкой, которая может происходить за счет смещений и поворотов Мn-содержащих бипирамид. Такое фазовое превращение является промежуточным между сегнетоэлектрической и параэлектрической фазами.

\section{4. Выводы}

1. Изготовлены ТР системы $\mathrm{YCu}_{x} \mathrm{Mn}_{1-x} \mathrm{O}_{3} \mathrm{c} x=0.05$, $0.10,0.15$ по обычной керамической технологии. Синтез происходил с образованием жидких фаз эвтектического
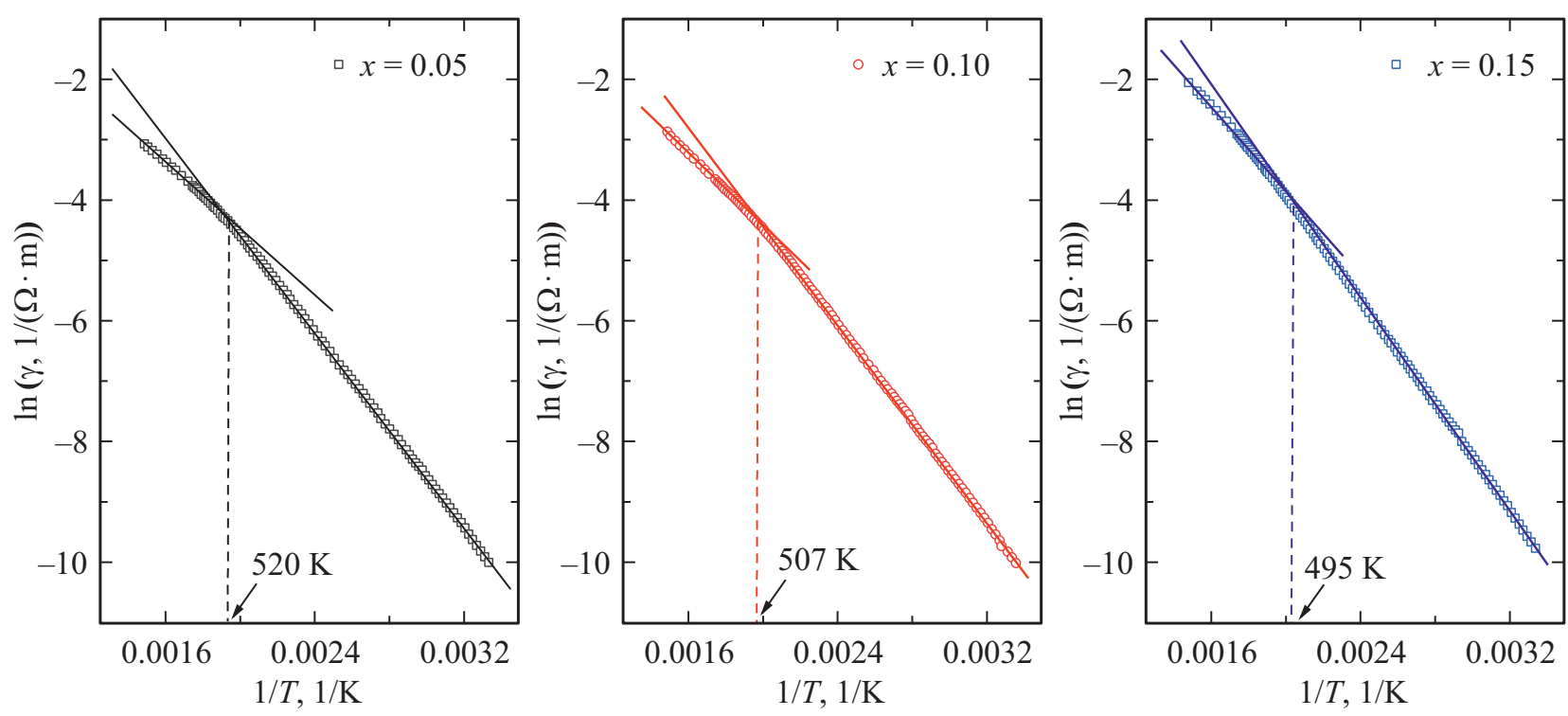

Рис. 7. Зависимости $\ln (\gamma)$ от $1 / T$ в интервале температур $25-400^{\circ} \mathrm{C}$ для ТР керамик $\mathrm{YCu}_{x} \mathrm{Mn}_{1-x} \mathrm{O}_{3}$ с $x=0.05,0.10$ и 0.15 . 
происхождения, признаки присутствия которых были выявлены при анализе микроструктуры материалов. Зерненое строение керамик является неоднородным, размер и форма кристаллитов разнообразны и варьируются широких пределах.

2. По данным РСА и РФА установлено, что с увеличением концентрации меди происходит снижение параметров ячейки, что говорит об образовании твердых растворов замещения. Обнаружено, что на фоне общего снижения объема существует аномальное поведение в длинах связи и валентных углах при $x=0.10$. Это возможно говорит о различной конфигурации валентных состояний марганца в $\mathrm{TP} \mathrm{YCu}_{x} \mathrm{Mn}_{1-x} \mathrm{O}_{3}$.

3. При анализе диэлектрических характеристик объектов выявлены аномалии на зависимостях $\varepsilon^{\prime} / \varepsilon_{0}(f, T)$ и $\operatorname{tg} \delta(f, T)$ при температурах $T=30-200^{\circ} \mathrm{C}$, обусловленные проявлением эффектов межслоевой поляризации из-за высокой электропроводности керамик, и на $\ln (\gamma)$ от $(1 / T)$ при $T=222^{\circ} \mathrm{C}\left(\mathrm{YCu}_{0.05} \mathrm{Mn}_{0.95} \mathrm{O}_{3}\right)$, $234^{\circ} \mathrm{C}\left(\mathrm{YCu}_{0.10} \mathrm{Mn}_{0.90} \mathrm{O}_{3}\right)$ и $247^{\circ} \mathrm{C}\left(\mathrm{YCu}_{0.15} \mathrm{Mn}_{0.85} \mathrm{O}_{3}\right)$, связанные с „изоструктурным“ переходом, являющимся промежуточным между сегнетоэлектрической и параэлектрической фазами.

4. Полученные результаты целесообразно использовать при синтезе и разработке материалов на основе $\mathrm{YMnO}_{3}$.

\section{Финансирование работы}

Работа осуществлялась в рамках государственного задания ЮНЦ РАН № госрегистрации проекта 01201354247 на оборудовании ЦКП ЮНЦ РАН (№ 501994).

\section{Конфликт интересов}

Авторы заявляют, что у них нет конфликта интересов.

\section{Список литературы}

[1] N.A. Spaldin, M. Fiebig. Science 309, 391 (2005).

[2] M. Fiebig. J. Phys. D38, R123 (2005).

[3] V.M. Goldschmidt. Geochemisca veterlun. Norske Videnkap, Oslo (1927).

[4] K. Uusi-Esko, J. Malm, N. Imamura, H. Yamauchi, M. Karppinen. Mater. Chem. Phys. 112, 1029 (2008).

[5] A. Filippetti, N.A. Hill. Phys. Rev. B 65, 195, 120 (2002).

[6] B.B. Van Aken, T.T.M. Palstra, A. Filippetti, N.A. Spaldin. Nature Mater. 3, 164 (2004).

[7] T. Lonkai, D.G. Tomuta, U. Amann, J. Ihringer, R.W.A. Hendrix, D.M. Tobbens, J.A. Mydosh. Phys. Rev. B 69, 13, 134108 (2004).

[8] Z.J. Huang, Y. Cao, Y.Y. Sun, Y.Y. Xue, C.W. Chu. Phys. Rev. B 56, 4, 2623 (1997).

[9] H.C. Gupta, P. Ashdhir. Physica B: Condens. Matter 262, $1-2,1(1999)$.

[10] S.A. Prokudina, Y.S. Rubinchik, M.M. Pavlyuchenko. Inorgan. Mater. 12, 598 (1976).
[11] C. Moure, J. Tartaj, A. Moure, O. Pena. Boletin de la Sociedad Espanola de Ceramica y Vidrio 48, 199 (2009).

[12] Г.Б. Бокий. Кристаллохимия. Наука, М. (1971). 400 с.

[13] А.В. Павленко, А.В. Турик, Л.А. Резниченко, Ю.С. Кошкидько. ФТТ 56, 6, 1093 (2014).

[14] C. Moure, D. Gutierrez, O. Pena, P. Duran. J. Solid State Chem. 163, 377 (2002).

[15] A.V. Nazarenko, K.G. Abdulvakhidov, A.V. Pavlenko. Sci. South Rus. 15, 4, 12 (2019).

[16] A.G. Razumnaya, A.V. Nazarenko, A.G. Rudskaya, M.F. Kupriyanov. Nano-Microsystems Technol. 8, 21 (2013).

[17] Ю.Д. Третьяков. Химия нестехиометрических окислов. МГУ, М. (1974). 364 с.

[18] Х.А. Садыков, И.А. Вербенко, Л.А. Резниченко, А.Г. Абубакаров, Л.А. Шилкина. Экология промышленного производства 2, 44 (2013).

[19] Л.А. Резниченко, О.Н. Разумовская, Л.А. Шилкина, В.А. Алешин. В сб.: VП Междунар. семинар по физике сегнетоэлектриков-полупроводников. МП „Книга“, Ростов н/Д (1996). Вып. 6. С. 149-151.

[20] А.С. Богатин, А.В. Турик. Процессы релаксационной поляризации в диэлектриках с большой сквозной проводимостью. Феникс, Ростов н/Д (2013). 256 с.

[21] M. Tomczyk, P.M. Vilarinho, A. Moreira, A. Almeida. J. App. Phys. 110, 064116 (2011).

[22] C.J. Fennie, K.M. Rabe. Phys. Rev. B 72, 100103 (2005).

Редактор Т.Н. Василевская 